\section{Putting the Wnt up colon cancer}

\author{
Lukas JAC Hawinkels, James CH Hardwick
}

If there is one cancer signalling pathway that Gut readers should be comfortable with, it is the Wnt pathway. Central to this pathway is the adenomatous polyposis coli (APC) gene responsible for familial adenomatous polyposis. Identification of the APC gene in 1991 heralded the start of an ongoing period of exponential growth in our understanding of the molecular basis of cancer, particularly of the large bowel. Clinicians can perhaps be forgiven for finding the ever-expanding list of genes and interacting pathways with their inaccessible names and acronyms daunting. For many, the paper in this issue by Elvira Bakker and coworkers at the Netherlands Cancer Institute revealing the detailed role of RSPO3 in colorectal carcinogenesis may only serve to widen the expanding clinician-researcher divide. However, those brave enough to dive deeper into this paper will be rewarded with an insight into the current state of the art of molecular research into colorectal cancer with an intriguing mix of confirmation of what we thought we knew and findings that challenge previous assumptions.

R-spondin 3 (RSPO3) is a secreted protein that acts to potentiate Wnt signalling. RSPOs first attracted attention as being specific ligands of the LGR5 (leucine-rich repeat-containing G-protein-coupled receptor 5) receptor. LGR5 is the marker for intestinal stem cells first described by Hans Clevers. LGR5 was itself identified in a screen for Wnt pathway targets in the intestine. So in a sense we have come full circle investigating a ligand, RSPO3, which impacts on the quintessential colon cancer pathway, the Wnt pathway, and itself discovered through a detailed investigation of Wnt signalling. But why investigate a ligand that is seemingly once removed from the action? For biologists, the mountaineers' adage 'because it's there' might suffice, but Gut readers will ask how is this likely to impact clinical practice?

RSPO-activating translocation mutations have been recently found in around 10\%

Department of Gastroenterology and Hepatology, Leiden University Medical Centre, Leiden, The Netherlands

Correspondence to Dr James CH Hardwick, Department of Gastroenterology and Hepatology, Leiden University Medical Centre, Albinusdreef 2, P.O. Box 9600, 2300 RC Leiden, The Netherlands; j.c.h.hardwick@lumc.nl of human colorectal cancers ${ }^{1}$ and these tumours respond to RSPO-neutralising antibodies. $^{2}$ RSPO3 mutations occur mutually exclusive with other classical Wnt-activating mutations (eg, in $A P C$ or CTNNB1 (the gene for $\beta$-catenin)), suggesting that RSPO3 mutations can substitute for them with a similar net effect on Wnt signalling and oncogenesis. Furthermore, RSPO may potentially represent a handle by which to pharmacologically target the notoriously 'undruggable' Wnt pathway. ${ }^{3}$ The problem with the Wnt pathway itself is that it is corrupted by pathway-activating mutations downstream of the Wnt ligands and receptors. Most successful molecularly targeted therapies to date have been aimed at ligands or their receptors. The mutated intracellular signal transduction elements of the pathway such as APC and $\beta$-catenin are tricky therapeutic targets. Recent work in a broader array of tumour types suggests that an RSPO-based therapy may have a bright future. ${ }^{4}$

Further tantalising insights come from the analysis of serrated polyps. The most aggressive colorectal cancers develop from serrated polyps via the serrated pathway ${ }^{5}$ and follow a different molecular chain of events than the classical Vogelstein adenoma-to-carcinoma molecular model, with no classical Wnt pathway mutations. Late recognition of serrated polyps and familial forms of serrated polyposis has meant that molecular understanding of the serrated pathway lags behind that of classical adenomas. RSPO3-activating mutations have recently been found to occur very frequently $(30 \%)$ in serrated polyps. ${ }^{6}$ Could this explain their aggressive nature?

What have the Dutch researchers done? Using advanced genetically modified mouse models, they have ensured that mice, after receiving tamoxifen, express large amounts of RSPO3 specifically in stem cells thereby mimicking the effects of the human RSPO3 mutations. Within only 2 months, these mice develop dramatic changes in their intestine with widespread hyperplasia and grossly disrupted cryptvillus architecture. They do not use the term 'serrated'. However, the morphological characteristics of serrated architecture have not been clearly defined in animal models ${ }^{7}$ and agreement among pathologists is poor even in human lesions. ${ }^{8}$ The mice also develop multiple adenomas and even invasive carcinomas, something that is rarely seen in mice where only a single gene is altered. Intriguingly, the expected high levels of Wnt pathway activity were absent as judged by nuclear accumulation of $\beta$-catenin. A further analysis using RNA sequencing confirmed only modest increases in Wnt signalling-related genes. While perhaps unexpected, this would fit well with the previous evidence published in Gut that there is a subtle relationship between levels of Wnt signalling and polyp development. ${ }^{9}$ More Wnt signalling does not translate directly into more polyps and cancer. The lower levels of Wnt signalling induced by RSPO3-activating translocations may be 'just right' in this respect. Does this mean that therapeutic efforts to lower Wnt signalling could have unexpected adverse effects?

The paper goes on to use lineagetracing methods to assess which cells turn into the polyps and cancers they find. By expressing RSPO3 specifically in stem cells, one might expect expansion of the stem cell pool and that polyps and cancers also arise from these cells. Surprisingly, there was little expansion of the stem cell compartment in contrast to the traditional APC-mutant models. ${ }^{9}$ RSPO3 seems to act predominantly on non-stem cells in the intestine via an alternative more widely expressed receptor, LGR4. The final surprise is the effect of adding in mutant KRAS on top of increased RSPO3. In human tumours, mutations in RSPO3 are always found in conjunction with KRAS or BRAF mutations. The KRAS mutations have been added on top of multiple other single colorectal cancer gene manipulations in mice (APC, TGFBRII, PTEN and $C D K N 2 A$ ) and consistently lead to a more aggressive phenotype. ${ }^{10}$ It would therefore be expected that the addition of a KRAS mutation would increase the number of invasive tumours. However, this was not seen. What is apparent is that RSPO3 and KRAS show additive effects as far as the hyperplastic phenotype is concerned.

In summary, this paper confirms RSPO as an important driver mutation in colorectal cancer and as such it represents an attractive target for new therapies.

\section{Competing interests None.}

Provenance and peer review Commissioned; externally peer reviewed.

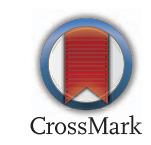

To cite Hawinkels LJAC, Hardwick JCH. Gut 2017;66:983-984. 


\section{Commentary}

Received 23 August 2016

Revised 26 October 2016

Accepted 27 October 2016

Published Online First 10 November 2016

\section{SLinked}

- http://dx.doi.org/10.1136/gutjnl-2016-311606

Gut 2017;66:983-984.

doi:10.1136/gutjnl-2016-312584

\section{REFERENCES}

1 Seshagiri S, Stawiski EW, Durinck S, et al. Recurrent $\mathrm{R}$-spondin fusions in colon cancer. Nature 2012:488:660-4.
2 Storm EE, Durinck S, de Sousa e Melo F, et al. Targeting PTPRK-RSPO3 colon tumours promotes differentiation and loss of stem-cell function. Nature 2016:529:97-100.

3 Garber K. Drugging the Wnt pathway: problems and progress. J Natl Cancer Inst 2009;101:548-50 (United States).

4 Chartier C, Raval J, Axelrod F, et al. Therapeutic targeting of tumor-derived R-spondin attenuates beta-catenin signaling and tumorigenesis in multiple cancer types. Cancer Res 2016;76:713-23.

5 De Sousa EMF, Wang $X$, Jansen $M$, et al.

Poor-prognosis colon cancer is defined by a molecularly distinct subtype and develops from serrated precursor lesions. Nat Med 2013;19:614-8.

6 Sekine S, Yamashita S, Tanabe T, et al. Frequent PTPRK-RSPO3 fusions and RNF43 mutations in colorectal traditional serrated adenoma. J Pathol 2016:239:133-8.

7 Washington MK, Powell AE, Sullivan R, et al. Pathology of rodent models of intestinal cancer: progress report and recommendations. Gastroenterology 2013;144:705-17.

8 Wong NA, Hunt LP, Novelli MR, et al. Observer agreement in the diagnosis of serrated polyps of the large bowel. Histopathology 2009;55:63-6.

9 Lewis A, Segditsas S, Deheragoda M, et al. Severe polyposis in Apc(1322T) mice is associated with submaximal Wnt signalling and increased expression of the stem cell marker Lgr5. Gut 2010:59:1680-6.

10 Jackstadt R, Sansom OJ. Mouse models of intestinal cancer. J Pathol 2016:238:141-51. 


\section{GUT Putting the Wnt up colon cancer}

Lukas JAC Hawinkels and James CH Hardwick

Gut 2017 66: 983-984 originally published online November 10, 2016 doi: 10.1136/gutjnl-2016-312584

Updated information and services can be found at:

http://gut.bmj.com/content/66/6/983

\section{These include:}

References This article cites 10 articles, 3 of which you can access for free at: http://gut.bmj.com/content/66/6/983\#BIBL

Email alerting

Receive free email alerts when new articles cite this article. Sign up in the service box at the top right corner of the online article.

\section{Notes}

To request permissions go to:

http://group.bmj.com/group/rights-licensing/permissions

To order reprints go to:

http://journals.bmj.com/cgi/reprintform

To subscribe to BMJ go to:

http://group.bmj.com/subscribe/ 